\title{
Respiratory Sensations in Dynamic Hyperinflation: Physiological and Clinical Applications
}

\author{
Morgan I Soffler MD, Margaret M Hayes MD, and Richard M Schwartzstein MD
}

\author{
Introduction \\ The Pathophysiology of Dynamic Hyperinflation \\ The Equal-Pressure Point and Flow Limitation \\ Time Constant \\ An Increase in Duty Cycle \\ The Physiology of Dyspnea \\ Dynamic Hyperinflation and Dyspnea \\ Inspiratory Threshold Load \\ A Decrease in Lung and Chest Wall Compliance at Higher Lung Volumes \\ Decreased Ventilatory Efficiency \\ Cardiocirculatory Consequences of Dynamic Hyperinflation \\ Tachypnea: A Maladaptive Response to Dyspnea in Dynamic \\ Hyperinflation \\ Measuring Exertional Dyspnea Related to Dynamic Hyperinflation \\ Management of Dyspnea Related to Dynamic Hyperinflation: A \\ Mechanistic Approach \\ Pharmacotherapy \\ Breathing Techniques and Pulmonary Rehabilitation \\ Continuous Positive Airway Pressure \\ Addressing the Affective and Emotional Dimension of Dyspnea \\ Lung Volume Reduction \\ Conclusion
}

Dynamic hyperinflation is a common cause of dyspnea and functional limitation in patients with emphysema. Dynamic hyperinflation occurs in individuals with air-flow limitation when expiratory time is decreased during periods of relative tachypnea (such as during exercise or agitation, for example). In this setting, patients with emphysema develop lung hyperinflation, impairment of inspiratory respiratory muscles, and an increase in work of breathing. The associated decrease in inspiratory capacity results in the stimulation of several receptors, including chemoreceptors and pulmonary receptors, which signal the brain to increase tidal volume. The inability of the respiratory system to respond to signals of increased demand (eg, by enlarging tidal volume and increasing inspiratory flow) results in a dissociation between afferent and efferent signaling thereby intensifying breathing discomfort, or what clinicians term dyspnea. A thorough understanding of the physiology of dyspnea and pathophysiology of dynamic hyperinflation informs the interventions used to mitigate sensations of dyspnea and the physiologic effects of dynamic hyperinflation, respectively. Pharmacotherapy, pulmonary rehabilitation, breathing techniques, positive airway pressure, and lung volume reduction are well-studied interventions that target pathways to dyspnea in patients with dynamic hyperinflation. Key words: dynamic hyperinflation; air-flow limitation; dyspnea; inspiratory threshold load; inspiratory capacity; neuroventilatory dissociation. [Respir Care 2017;62(9):1212-1223. (C) 2017 Daedalus Enterprises] 


\section{Introduction}

Dyspnea is a debilitating symptom affecting millions of individuals in both in-patient and out-patient settings, with varying levels of acuity. It is formally defined as a subjective experience of breathing discomfort that consists of qualitatively distinct sensations that vary in intensity. ${ }^{1}$ Dynamic hyperinflation, a contributor to dyspnea in patients with COPD, often goes unrecognized. Dynamic hyperinflation occurs when a breath is initiated prior to complete exhalation of the previous breath, resulting in an increase in end-expiratory lung volume and subsequent restrictions on inspiratory capacity. ${ }^{2}$ Dynamic hyperinflation can contribute to both acute and chronic dyspnea in patients with obstructive lung disease in a variety of clinical scenarios. Dynamic hyperinflation and exercise impairment have been shown to be independent predictors of mortality in individuals with COPD. ${ }^{3,4}$

Emphysema, which is characterized by both structural and functional impairment of the lung, is the most common obstructive lung disease associated with dynamic hyperinflation. In emphysema, destruction of the alveolar wall results in a decrease in elasticity of the lung, often resulting in static hyperinflation as the balance of forces between the lung and chest wall are altered at total lung capacity and functional residual capacity. In addition, small airways in the lung are supported or tethered open by surrounding lung tissue. Loss or weakening of these supports results in increased airway resistance when pleural pressure is elevated during forced exhalation, creating the potential for expiratory air-flow limitation. ${ }^{5}$ Functionally, the destruction of alveolar walls in emphysema reduces gas exchange capabilities by leading to ventilation-perfusion inequality and by reducing the capillary-alveolar surface area for diffusion of oxygen. Both static hyperinflation and air-flow limitation leading to dynamic hyperinflation have been shown to contribute greatly to dyspnea in COPD, ${ }^{6}$ and resting hyperinflation is a strong predictor of exercise impairment in patients who develop

Dr Soffler is affiliated with Massachusetts General Hospital and Beth Israel Deaconess Medical Center Combined Fellowship in Pulmonary and Critical Care Medicine, Harvard Medical School, Boston, Massachusetts. Drs Hayes and Schwartzstein are affiliated with the Division of Pulmonary and Critical Care Medicine and the Carl J Shapiro Institute for Education and Research at Beth Israel Deaconess Medical Center, Harvard Medical School, Boston, Massachusetts.

The authors have disclosed no conflicts of interest.

Correspondence: Morgan I Soffler MD, Carl J. Shapiro Institute for Education and Research, Beth Israel Deaconess Medical Center, 330 Brookline Avenue Boston, MA 02215. E-mail: msoffler@bidmc.harvard.edu.

DOI: $10.4187 /$ respcare. 05198 dynamic hyperinflation. ${ }^{7}$ Exercise limitation is a common and often debilitating symptom in patients with COPD. ${ }^{8}$

\section{The Pathophysiology of Dynamic Hyperinflation}

\section{The Equal-Pressure Point and Flow Limitation}

Dynamic hyperinflation develops when there is expiratory air-flow limitation in the face of decreased time for exhalation. Expiratory flow is determined by airway resistance and driving pressure for air movement (which is the difference between mouth and alveolar pressure). During exhalation, pressure in the airway falls as air flows from the alveolus to the mouth due to three factors: (1) airway resistance, (2) the acceleration of gas as it moves from multiple small airways in parallel to fewer larger airways (Bernoulli's principle), and (3) the transition from laminar to turbulent flow associated with the increased velocity of gas resulting from movement from the peripheral to the central airways and the consequent diminution in the crosssectional area of the airways in parallel. During a forced exhalation, as the airway pressure decreases along its path from the alveolus to the mouth, it will eventually decrease to the point where it matches the pleural pressure (the pressure outside of the airway).

The point at which transmural pressure is zero is the equal-pressure point. In this model, further reduction in airway pressure below the pleural pressure results in collapse of the airway and cessation of flow. In this static condition (ie, no flow), the alveolar pressure (which is the sum of the pleural pressure and the elastic recoil pressure) re-equilibrates with the pressure in the airway proximal to the collapse. The pressure inside of the airway is once again greater than the pleural pressure and the airway opens and expiratory flow resumes. As air flow continues, however, the airway pressure will again drop, creating a cycle with repeated airway opening and closing. ${ }^{9,10}$

In these conditions, the driving pressure for flow is no longer determined by the difference between alveolar and mouth pressure, but by alveolar and pleural pressure (the pressure responsible for reopening the airway at the equalpressure point). Because any increase in pleural pressure results by definition in an increase in alveolar pressure, increasing pleural pressure by increasing expiratory respiratory effort will not increase the driving pressure and therefore will not increase expiratory flow. This condition is called expiratory air-flow limitation ${ }^{11}$ (Fig. 1).

\section{Time Constant}

The lungs' ability to empty back to their baseline functional residual capacity is related to both expiratory flow and the time allowed for exhalation, and this ability depends upon each individual's lung mechanics, both com- 


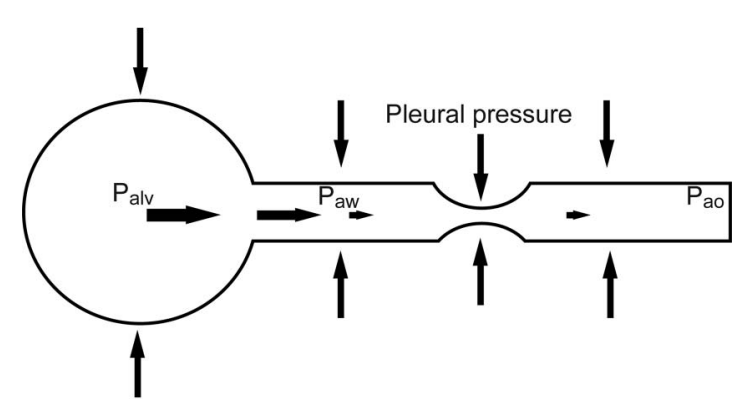

Fig. 1. The equal-pressure point model and expiratory flow limitation. As expiratory air flows from the alveolus to the airway opening, $\mathrm{P}_{\text {aw }}$ will decrease from $\mathrm{P}_{\text {alv }}$ (depicted by the horizontal arrows). At a certain point along the airway, $P_{a w}$ decreases to where it is equal to pleural pressure and will collapse. At the equal-pressure point, the driving pressure for flow becomes the pressure difference between $\mathrm{P}_{\text {alv }}$ and pleural pressure. Any increase in pleural pressure (depicted by the vertical arrows) will be transmitted to the alveoli as well as well as the airway and therefore will not influence expiratory flow. Flow resumes when $\mathrm{P}_{\text {alv }}$ re-equilibrates with $\mathrm{P}_{\text {aw }}$ and the cycle of airway closing and opening continues. $\mathrm{P}_{\text {alv }}=$ alveolar pressure; $\mathrm{P}_{\mathrm{aw}}=$ airway pressure; $\mathrm{P}_{\mathrm{ao}}=$ airway opening pressure.

pliance of the lung (which affects the recoil force of the lung) and resistance of the airways. The product of compliance and resistance is called the time constant. The time constant is a theoretical construct that provides insight into how long an alveolus takes to exchange the gas (fill and empty) within it; low compliance (strong recoil) and low resistance lead to high flows and low time constants. Individuals with emphysema have an increase in compliance and airway resistance, both of which directly increase the time constant and thereby result in an abnormally long time for complete exhalation. ${ }^{10}$

\section{An Increase in Duty Cycle}

The duty cycle is the ratio of inspiratory time to the total time of the respiratory cycle. At rest, the duty cycle is roughly one third of the total respiratory cycle. When we increase our breathing frequency, we decrease expiratory time out of proportion to inspiratory time, resulting in an increase in duty cycle. Thus, an increase in breathing frequency results in shortened time for exhalation and leads to incomplete emptying of alveoli prior to initiation of the next breath if one is unable to increase expiratory flow; that is, if flow limitation is present, end-expiratory volume increases and the next breath starts at a higher volume (Fig. 2).

With each succeeding breath, the end-expiratory volume increases further until a new steady state is reached. Steady state, in this circumstance, means that the volume of gas exhaled equals the volume inhaled and end-expiratory lung volume remains constant. To achieve steady state,

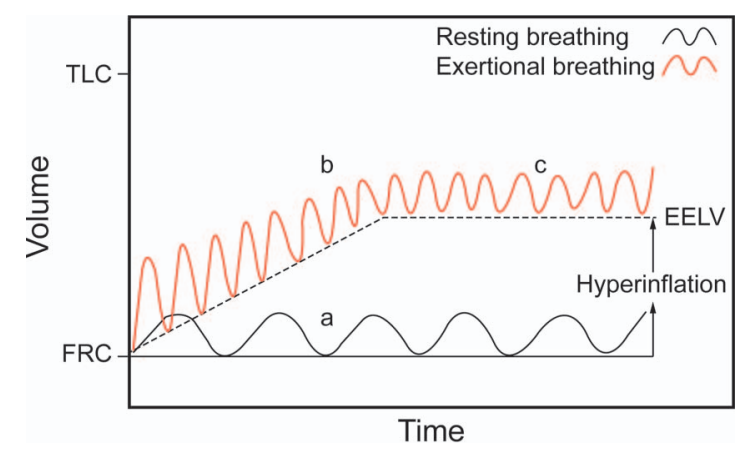

Fig. 2. Dynamic hyperinflation and a new steady state at a higher lung volume. (a) Resting breathing (solid line): a breath is inhaled to tidal volume and exhaled to FRC, also known as the relaxation volume of the lung. (b) Breathing during exertion, agitation, or anxiety: the tidal volume and breathing frequency increase (the dotted line) with a diminution in expiratory time. The inspiratory volume is greater than the expiratory volume and results in a larger end-expiratory volume with each breath, (c) a new steady state: eventually, a new steady state is reached due to an increase in airway diameter and elastic recoil at higher lung volumes, both of which contribute to higher expiratory flow. TLC = total lung capacity; $F R C$ = functional residual capacity; EELV = end-expiratory lung volume.

expiratory flow must increase. How can this occur if the patient is flow-limited?

This new steady state (and higher expiratory flow) is achieved when the lung volume increases to the point that the radius of the airway (which is determined by lung volume) is sufficiently enlarged such that resistance is now reduced, and elastic recoil (driving force for exhalation under conditions of flow limitation) is increased. Together, these changes (greater driving force and lower resistance) result in an increase in flow that will allow the volume of gas inhaled to be exhaled in the allotted time. End-expiratory volume reaches a new plateau, and the new end-expiratory lung volume remains above the original relaxation volume of the lung (Fig. 2).

Whether it is exertion, anxiety, agitation, or respiratory distress, any increase in breathing frequency in the setting of airway resistance and expiratory flow limitation can result in dynamic hyperinflation. Even in the absence of expiratory flow limitation, patients with exacerbations of COPD are at risk for developing dynamic hyperinflation due to the increase in baseline airway resistance, long time constant, and exertional breathing pattern that increases tidal volume and reduces expiratory time. ${ }^{12}$

\section{The Physiology of Dyspnea}

To understand the mechanisms by which dynamic hyperinflation contributes to dyspnea, we will review the physiologic sources of common respiratory sensations that are often grouped together under the common clinical description of dyspnea. 


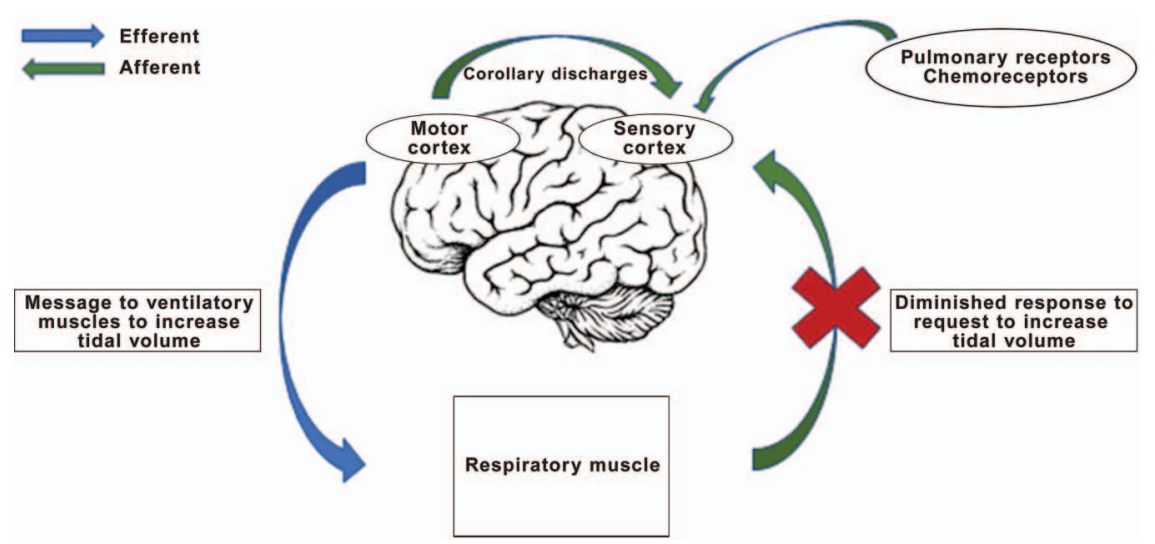

Fig. 3. Efferent-reafferent dissociation, also known as neuroventilatory dissociation. While tidal volume is shown in the boxes, other associated parameters (eg, flow, pressure changes in the thorax, tension generated in the inspiratory muscles, shortening of inspiratory muscles) are dictated by the output from the motor cortex and monitored by the sensory cortex.

The sensation of dyspnea most often starts with a physiologic impairment that alters the function of the respiratory pump, increases the work of breathing, and reduces the ability to achieve appropriate flow, volume, and gas exchange. Consequently, stimulation of various afferent receptors is altered, resulting in dyspnea. The relevant afferent receptors comprise (1) chemoreceptors, (2) chest wall, and (3) pulmonary receptors. We must also consider corollary discharges, which involve neural messages sent from the motor to the sensory cortex; the intensity of these discharges correlates with increased neural output to the ventilator muscles. The phenomenon called efferent-reafferent dissociation, or neuroventilatory dissociation ${ }^{10,13-15}$ is associated with impairment of the ventilatory pump and has a direct effect on dyspnea. ${ }^{16}$ Historically, this was first conceived as length-tension inappropriateness, a term denoting that the perception of effort (emanating from central drive) increased when ventilatory muscles generated tension with relatively little shortening due to increased airway resistance or decreased compliance of the lungs and chest wall. The consequence was stimulation of muscle spindles alerting the sensory cortex to the fact that the respiratory system had not performed as expected for the neural output of the motor cortex; the result was the perception of increased effort of breathing and dyspnea. This concept has now been broadened to take into account not only neural input from muscle spindles but from other structures that monitor expansion of the lung and chest wall and inspiratory flow (Fig. 3).13 The increased neural messages subsequently sent from the motor to the sensory cortex, which lead to the sense of effort, are associated with increased neural discharge to the ventilatory muscles.

Pulmonary receptors, physically located within the lungs, stimulate the respiratory controller when they are either over- or underactivated. The pulmonary stretch receptors respond to both inflationary and deflationary influences, for example, and may be stimulated by a lack of stretch (or low tidal volume). Other pulmonary receptors, such as C fibers and rapidly adapting receptors, are stimulated by chemicals and mediators of inflammation. Chemoreceptors include those receptors in the carotid bodies and brainstem that perceive changes in $\mathrm{P}_{\mathrm{aO}_{2}}, \mathrm{P}_{\mathrm{aCO}_{2}}$, and acidemia and stimulate the respiratory control center to increase ventilatory drive in conditions of hypoxemia, hypercapnia, and acidemia, respectively. ${ }^{17}$ Upon stimulation of the respiratory center by these afferent signals, a neural impulse is sent from the motor cortex to the ventilatory muscles to contract, and a corollary discharge signal is sent from the motor cortex to sensory cortex. A corollary discharge is a copy of the signal that sends an efferent message from the motor cortex to the ventilatory muscle and is thought to be responsible for the sense of effort associated with an increase in ventilator drive. ${ }^{18}$ Efferent-reafferent dissociation describes the mismatch between outgoing signals from the respiratory controller and the response from the components of the respiratory symptom (eg, change in flow, pressure, volume) that can occur in various pathological states. The term reafferent is used because it is in response to the original efferent motor signal. ${ }^{10}$ Stated otherwise, there is a mismatch between the drive to breathe and the response of the respiratory system that causes neuroventilatory dissociation. Expressed as a sensory term, efferent-reafferent dissociation is mostly closely aligned with the sense of effort or work of breathing but may increase the intensity of air hunger, which arises when there is an increase in respiratory drive and is among the most unpleasant types of dyspnea described. ${ }^{16}$

Investigators have been able to isolate some of these pathways and can attribute particular afferent outputs to particular patient descriptions of dyspnea. For example, patients with asthma characteristically describe chest tightness, which has been shown to be independent of the work of breathing and is believed to arise from stimulation of pulmonary receptors. For example, patients with conges- 
tive heart failure often report suffocating. ${ }^{19-22}$ The observation of associations of clusters of patient descriptions of dyspnea with particular disease states supports the theory that these various afferent pathways may be involved in the production of dyspnea; hence, different pathophysiology leads to different sensations. Clinically, multiple afferent pathways and receptors are likely involved in concert to produce what are often multiple qualitatively distinct sensations. ${ }^{23}$ Patients' descriptions of dyspnea quality and changes in dyspnea quality are important clues to the underlying pathophysiology. Dynamic hyperinflation provides an example of a process involving multiple afferent pathways along with an increase in respiratory drive, and may result in variety of unpleasant respiratory sensations including air hunger, an inability to get a deep breath, an unsatisfying breath, and an increased effort and work of breathing.

\section{Dynamic Hyperinflation and Dyspnea}

In the case of dynamic hyperinflation, several physiologic impairments contribute to stimulation of afferent pathways to cause dyspnea. The most notable physiologic consequence of dynamic hyperinflation can be understood by exploring the change in pulmonary mechanics that occurs when an individual must initiate a breath at a higher endexpiratory lung volume, and the sensations generated when inspiratory capacity is limited. ${ }^{24}$ Studies suggest that the intensity of dyspnea is more closely correlated with the degree of dynamic hyperinflation than with air-flow limitation. ${ }^{22}$

\section{Inspiratory Threshold Load}

In dynamic hyperinflation, the brain signals the inspiratory muscles to contract before the lung reaches its relaxation volume (ie, functional residual capacity); pressure in the airways is still positive, that is, greater than pressure at the mouth. The positive pressure in the alveoli and airways at the end of exhalation is called intrinsic PEEP. For air to flow from the mouth to the alveoli during inspiration, the alveolar pressure must be negative relative to atmospheric pressure. Thus, inspiratory flow does not begin immediately when the diaphragm is stimulated; rather, pressure in the alveolus must first be reduced from the PEEP level to zero. The added end-expiratory pressure due to dynamic hyperinflation, which has been called an inspiratory threshold load, increases the amount of work the patient must do to generate a breath. The increased inspiratory threshold load potentiates neuroventilatory dissociation by both leading to an increase in central drive to breathe as well as the lag between effort for inspiration and actual inflation of the respiratory system. Oxygen demand is also increased in this setting. 2,25

\section{A Decrease in Lung and Chest Wall Compliance at Higher Lung Volumes}

As the respiratory system operates at increasingly high volumes, the compliance of both the lungs and chest wall decreases; more pressure is needed to achieve an increase in volume, leading to an increase in the work of the inspiratory muscles. ${ }^{26}$ This can be experienced by taking a deep breath to a volume just below total lung capacity and then attempting a subsequent tidal ventilation from this resting point. Doing so alters the force-length relationship of the inspiratory muscles by creating a geometric disadvantage, whereby the muscles contracting from a shortened length results both in reduced pressure generation and chest displacement despite increased efferent drive. ${ }^{27}$ When the drive to breathe is increased, leading to a sensation of air hunger, ${ }^{28}$ dyspnea is worsened if tidal volume is restricted.

\section{Decreased Ventilatory Efficiency}

The idea that hypercapnia in COPD is the direct result of inspiratory muscle fatigue has not been proven in the literature. Likewise, a chronic decrease in ventilatory drive in this population has not been seen. In fact, studies have shown that in subjects with COPD and hypercapnia, respiratory drive is at least preserved or even magnified. ${ }^{29,30}$ Rather, the development of hypercapnia in patients with COPD during exertion is thought to be related to ventilatory inefficiency from the mechanical constraints on ventilation as a consequence of dynamic hyperinflation. ${ }^{31}$ The decrease in tidal volume generated by the disadvantaged inspiratory muscles and decreased compliance of the respiratory system, particularly as end-inspiratory volume nears total lung capacity, increases the ratio of physiologic dead space over tidal volume $\left(\mathrm{V}_{\mathrm{D}} / \mathrm{V}_{\mathrm{T}}\right)$, minimizing alveolar ventilation, increasing the subsequent need for total ventilation, and potentially leading to worsening hypercarbia and hypoxemia. ${ }^{32,33,34}$

\section{Cardiocirculatory Consequences of Dynamic Hyperinflation}

Cardiocirculatory impairment has become increasingly recognized as a contributor to exercise intolerance in patients with pulmonary hyperinflation. ${ }^{35}$ In a large group of COPD subjects, the degree of COPD severity correlated with cardiac dysfunction. ${ }^{36}$ The effect of the increase in alveolar and airway pressure in the face of increased endexpiratory lung volume is to increase the intrathoracic pressure. This added pressure is transmitted to the key structures in the thorax and can have significant functional consequences on the most compliant structures such as the right atrium and the great veins. High intrathoracic pres- 
sures may decrease filling pressure of the right and left ventricles and impair cardiac output. This has been demonstrated on cardiac magnetic resonance imaging, which showed a decrease in right and left ventricular diastolic volume in patients with dynamic hyperinflation. ${ }^{37}$ Venous return may also be influenced by expiratory abdominal muscle recruitment, which is augmented in pulmonary hyperinflation, causing a decrease in right ventricular filling pressures. ${ }^{38}$ The hemodynamic consequences of dynamic hyperinflation further limit exercise capacity due to inadequate oxygen delivery to exercising skeletal muscle. ${ }^{39-41}$ Interestingly, there has been an observed association between limited heart rate response to exercise, also known as chronotropic incompetence, and dynamic hyperinflation, which is not well understood. ${ }^{42}$

\section{Tachypnea: A Maladaptive Response to Dyspnea in Dynamic Hyperinflation}

The physiologic consequences of dynamic hyperinflation as outlined above provide stimuli for the various afferent pathways that contribute to dyspnea. The decrease in tidal volume due to the respective increase in inspiratory threshold load and decreased efficiency of the inspiratory muscles decreases the stimulation of pulmonary stretch receptors; the mechanical response of the respiratory system is less than expected. Corollary discharges from the motor cortex sent to the inspiratory muscles in an effort to increase tidal volume are left unanswered, resulting in significant efferent-reafferent dissociation. Simultaneously, the decrease in tidal volume and increase in dead space may contribute to hypoxemia, hypercapnia, and academia, causing activation of the respiratory center via stimulation of chemoreceptors (Fig. 4).

The sensation of dyspnea is brought to consciousness when efferent signals from the brain stem stimulate cortical and subcortical structures, mediated by the limbic and paralimbic centers, as well as the sympathetic nervous system. Both discriminative processing (what the sensation is) and affective processing (how the sensation feels) are part of the ultimate experience of dyspnea; the latter, which includes aversive experiences, involves the amygdala and its associated structures. ${ }^{43-45}$ Upon conscious processing, the sensation of dyspnea often evokes a range of strong emotional responses such as anxiety, distress, and fear, which may lead to maladaptive breathing patterns for the individual with flow limitation. Because dyspnea is sensed as distressing, the behavioral response is often to increase the breathing frequency. As time for exhalation decreases in response to the increased duty cycle, hyperinflation may worsen, causing a deleterious cycle of dyspnea, tachypnea, and hyperinflation. This will lead to more distress and anxiety. Metronome-paced tachypnea is a controlled method to artificially induce tachypnea and has

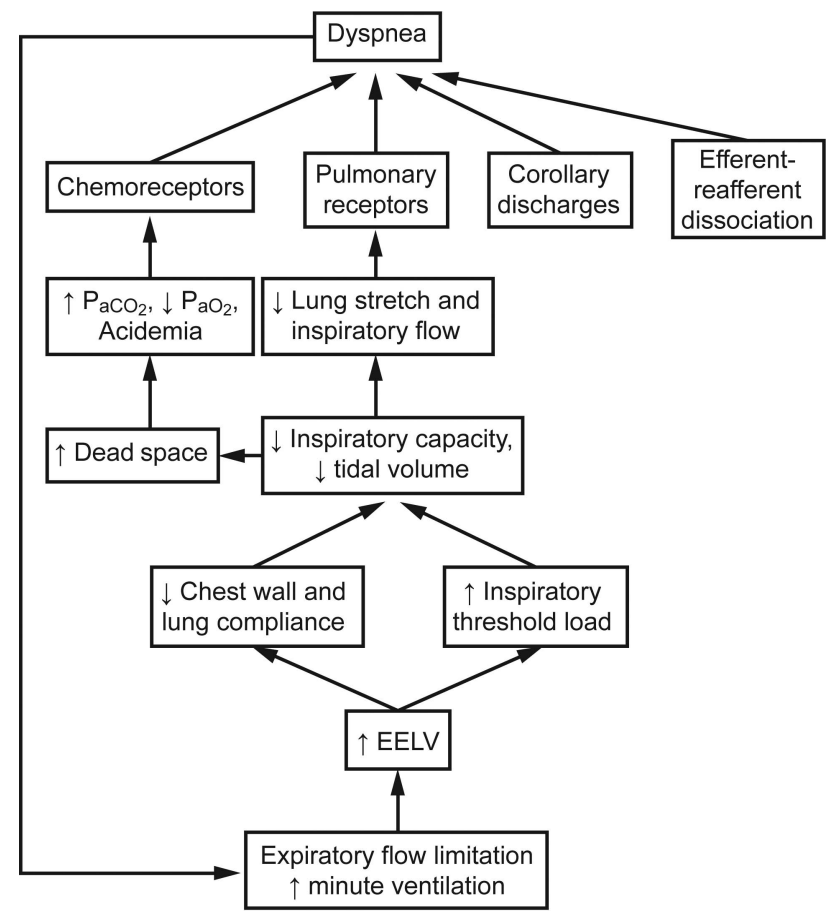

Fig. 4. The physiology of dyspnea in dynamic hyperinflation. EELV= end-expiratory lung volume.

been used to study the effects of tachypnea on respiratory mechanics. The effect of decreased expiratory time on the development of dynamic hyperinflation has been demonstrated during metronome-paced tachypnea in subjects with $\mathrm{COPD}^{46}$ and has been shown to have physiologic effects similar to those of incremental exercise in patients with expiratory flow limitation. ${ }^{47}$

\section{Measuring Exertional Dyspnea Related to Dynamic Hyperinflation}

Dynamic hyperinflation is often underappreciated by providers as a cause of exertional dyspnea and a contributor to acute respiratory decompensation. In part, this is because individuals with exertional dyspnea may unconsciously modify their daily routine to avoid activities that pose difficulty and may thus underreport their symptoms. In addition, resting pulmonary function tests do not capture the functional respiratory changes that occur as a result of exertion or tachypnea-related dynamic hyperinflation.

In an attempt to identify patients with hyperinflationrelated exertional dyspnea, several studies have explored the utility of functional testing to screen patients for dynamic hyperinflation. Measurements of inspiratory capacity and the ratio of end-expiratory lung volume to total lung capacity during exercise in subjects with COPD have been used to measure the degree of dynamic hyperinflation. ${ }^{2,24,25,48}$ Use of these measurements has been applied 
Table 1. Physiologic Mechanisms of Action of Treatments for Dyspnea Related to Dynamic Hyperinflation

\begin{tabular}{|c|c|c|c|c|c|}
\hline Treatments & $\begin{array}{l}\text { Decrease Expiratory } \\
\text { Flow Limitation }\end{array}$ & $\begin{array}{c}\text { Increase } \\
\text { Expiratory Time }\end{array}$ & $\begin{array}{l}\text { Decrease Inspiratory } \\
\text { Threshold Loading }\end{array}$ & $\begin{array}{l}\text { Increase Respiratory } \\
\text { Muscle Efficiency }\end{array}$ & $\begin{array}{l}\text { Decrease Perception } \\
\text { of Dyspnea }\end{array}$ \\
\hline Bronchodilators & $\sqrt{ }$ & & & & \\
\hline Inhaled furosemide & $\checkmark$ & & & & $\checkmark$ \\
\hline Pursed-lip breathing & $\checkmark$ & $\sqrt{ }$ & & & \\
\hline Positive expiratory & $\checkmark$ & & $\sqrt{ }$ & & \\
\hline \multicolumn{6}{|l|}{ Pressure therapy } \\
\hline Pulmonary & & $\sqrt{ }$ & & $\checkmark$ & \\
\hline \multicolumn{6}{|l|}{ Rehabilitation } \\
\hline Lung volume & $\checkmark$ & & $\checkmark$ & & \\
\hline \multicolumn{6}{|l|}{ Reduction surgery } \\
\hline Opioids & & $\sqrt{ }$ & & & $\sqrt{ }$ \\
\hline
\end{tabular}

in the out-patient setting using the 6-min walk test followed by measurements of inspiratory capacity to evaluate the contribution of dynamic hyperinflation to exertional dyspnea. 49,50

Cardiopulmonary exercise testing has been proposed as a method to evaluate patients' perceived dyspnea, exercise intolerance, and the potential factors contributing to their breathing discomfort. As expected, in individuals with even mild COPD, the abnormalities described include an increase in respiratory drive as well as an increase in intrinsic end-expiratory pressure leading to functional mechanical constraints and exertional dyspnea. In individuals with more severe disease, these effects are magnified and tend to occur earlier during exercise. ${ }^{51} \mathrm{~A}$ breakdown of the various components contributing to dyspnea may be elucidated, including cardiac causes, from formalized cardiopulmonary exercise testing to better target potential interventions.

Alternatively, metronome-paced tachypnea has been proposed as a potential screening tool to identify patients with dynamic hyperinflation. ${ }^{52,53}$ Both cardiopulmonary exercise testing and metronome-paced tachypnea have been studied as potential screening tools to identify patients with dynamic hyperinflation and have been able to identify patients who hyperinflate during activities of daily living. Metronome-paced tachypnea is simpler and less expensive; it has been found to be less sensitive, however, than cardiopulmonary exercise testing (sensitivities of $89 \%$ vs $96 \%$, respectively). ${ }^{54}$

\section{Management of Dyspnea Related to Dynamic Hyperinflation: A Mechanistic Approach}

Interventions to improve functional capacity and quality of life in patients with obstructive lung disease and dynamic hyperinflation target a variety of pathophysiologic pathways to decrease expiratory flow limitation, reduce end-expiratory lung volume, and improve inspiratory muscle strength and capacity (Table 1). Treating the sensation of dyspnea itself, with opioids for example, may have a role in patients with advanced disease as well as in those with acute dynamic hyperinflation.

\section{Pharmacotherapy}

Pharmacotherapy can be useful in the treatment of dyspnea. Categories of drugs include bronchodilators, opioids, and inhaled furosemide.

Bronchodilators. Bronchodilators, such as long-acting beta agonists and long-acting muscarinic agents, help mitigate the contribution of airway resistance and expiratory flow limitation to the development dynamic hyperinflation. ${ }^{55}$ Several studies have demonstrated the beneficial effect of inhaled bronchodilators on dynamic hyperinflation and exercise tolerance ${ }^{56-59}$. The use of tiotropium, specifically, has been associated with a reduction in hyperinflation both at rest and with exertion with subsequent improvement in tidal volume and exercise tolerance. ${ }^{58} \mathrm{Gly}$ copyrronium has been suggested to have some advantages as a faster and longer-acting bronchodilator and has been shown to effectively reduce lung hyperinflation in patients with COPD. ${ }^{60}$ The examination of breathing patterns after receiving bronchodilator therapy has demonstrated a slower and deeper respiratory pattern during exercise as well as improved cardiovascular response to exercise. ${ }^{61-63}$

Opioids. Opioid therapy has been shown to be effective in reducing the sensation of breathlessness in individuals with a variety of lung disorders. ${ }^{1,64-66}$ Two main mechanisms for the reduction of dyspnea with opioid therapy are suggested by laboratory experiments: (1) altered perception of dyspnea and a reduction of anxiety via direct action on central synapses, and (2) a reduction in respiratory drive and corollary discharges through action on the medullary respiratory centers. ${ }^{65,67}$ In combination, these effects alleviate the efferent-reafferent dissociation and affective response to dyspnea that may contribute to 
respiratory discomfort or distress. ${ }^{67}$ Opioid therapy for patients with refractory dyspnea is often only used as a palliative treatment for patients at the ends of their lives; however, it may be underutilized in patients with more stable disease who suffer from refractory or episodic dyspnea. Low-dose opioids have been shown to be effective in both episodic and chronic dyspnea in both in-patient and out-patient settings. ${ }^{66,68,69}$ Clinicians may be reluctant to prescribe opioids due to fear of adverse effect such as respiratory depression, falls, confusion, etc. ${ }^{70}$ Morphine, in doses of approximately $5 \mathrm{mg}$ intravenously, has been shown to reduce dyspnea without causing significant respiratory depression in normal subjects. ${ }^{64}$

In acute dynamic hyperinflation, low-dose morphine could be considered as an adjunctive treatment in the management of acute dyspnea in patients with obstructive lung disease. Though there are no controlled studies demonstrating that opioid therapy can mitigate dynamic hyperinflation by improving inspiratory capacity and lung mechanics, there have been cases of morphine mitigating the affective response and thereby improving lung mechanics and lessening acute dynamic hyperinflation. ${ }^{71}$ Opioids may blunt the perception of respiratory discomfort or distress, relieve anxiety, and slow the breathing frequency, thus providing more time for exhalation and reducing end-expiratory lung volume.

Inhaled Furosemide. Inhaled furosemide has been studied as a treatment for dyspnea and is believed to work via direct effect of the pulmonary stretch receptors, ${ }^{72,73}$ thereby improving efferent-reafferent dissociation, and by inducing bronchodilation. ${ }^{74}$ Primarily studied in terminally ill cancer subjects with dyspnea, furosemide was shown to reduce patient-perceived dyspnea, particularly sense of effort, independent of any contribution to diuresis. Breathing frequency in this patient population was unchanged, however. ${ }^{73}$ Several small studies evaluating the efficacy of inhaled furosemide in subjects with COPD have shown similar benefit. In a study of 20 subjects with COPD randomized to receive placebo versus furosemide, subjects who received inhaled furosemide reported an alleviated sensation of dyspnea induced by constant-load exercise testing. A significant bronchodilator response was also seen. ${ }^{74}$ Another study of inhaled furosemide in subjects with COPD showed an improvement in exercise endurance accompanied by an increase in dynamic inspiratory capacity, oxygen saturation, and oxygen uptake. ${ }^{75}$

\section{Breathing Techniques and Pulmonary Rehabilitation}

Pulmonary rehabilitation has been shown to improve inspiratory muscle strength, decrease dyspnea, and improve exercise capacity as well as central hemodynamic responses to exercise in subjects with $\mathrm{COPD}^{76-79}$. Pulmo- nary rehabilitation primarily addresses issues related to inspiratory muscle weakness and rapid and shallow breathing patterns that reduce the efficiency of breathing. Pulmonary rehabilitation programs may target muscle strengthening through incremental exercise training to strengthen both ventilatory and non-ventilatory skeletal muscles. Diaphragm movement during inhalation and exhalation, as assessed by fluoroscopy, has been shown to improve after pulmonary rehabilitation. ${ }^{80}$ Breathing techniques with a focus on slow, deep breaths in contrast to rapid shallow breathing helps alleviate effects of dynamic hyperinflation and improve exercise capacity. Muscle training and breathing techniques implemented in pulmonary rehabilitation settings have been shown to increase exercise tolerance and, more specifically, increase inspiratory capacity.

Breathing techniques can have a significant impact on exercise performance and dyspnea. Expiratory positive airway pressure, by way of pursed-lip breathing, is often used spontaneously in individuals with COPD but can also be taught as a tool for management of both acute and chronic hyperinflation. ${ }^{81}$ Pursed-lip breathing is a breathing technique by which a person exhales through tightly pressed, or pursed, lips. This technique may relieve air trapping by prolonging expiratory time and by encouraging a slower breathing frequency. The improvement in expiratory time causes a relative decrease in end-expiratory volume, thereby improving inspiratory capacity, alleviating inspiratory muscle work and thus reducing dyspnea. Figure 5 shows a chest roentgenogram of a patient with COPD who developed acute dynamic hyperinflation in the setting of agitation, with improvement after being coached through a pursed-lip breathing technique. The application of expiratory positive airway pressure has been shown to improve inspiratory capacity, ${ }^{82}$ exercise tolerance, ${ }^{83}$ and exertional oxygen saturation. ${ }^{84,85} \mathrm{~A}$ recent, small, randomized study evaluated the impact of directing an air current to the face of subjects with COPD during exercise and found that inspiratory capacity, exercise performance, and reported dyspnea improved. The proposed mechanism of this observed benefit is an alteration in the breathing pattern that diminished development of dynamic hyperinflation. ${ }^{86}$

\section{Continuous Positive Airway Pressure (CPAP)}

Noninvasive ventilation is a well-accepted therapy in patients with exacerbations of COPD as evidenced by randomized, controlled trials and is supported by worldwide clinical guidelines as a method to reduce mortality and endotracheal intubation rates. ${ }^{87,88}$ Its use for chronic dyspnea or exertional dyspnea associated with dynamic hyperinflation is less well-established. Several studies have evaluated the use of noninvasive ventilation with inspiratory pressure support, expiratory pressure, or both, and have found that its use may acutely reduce exertional dys- 

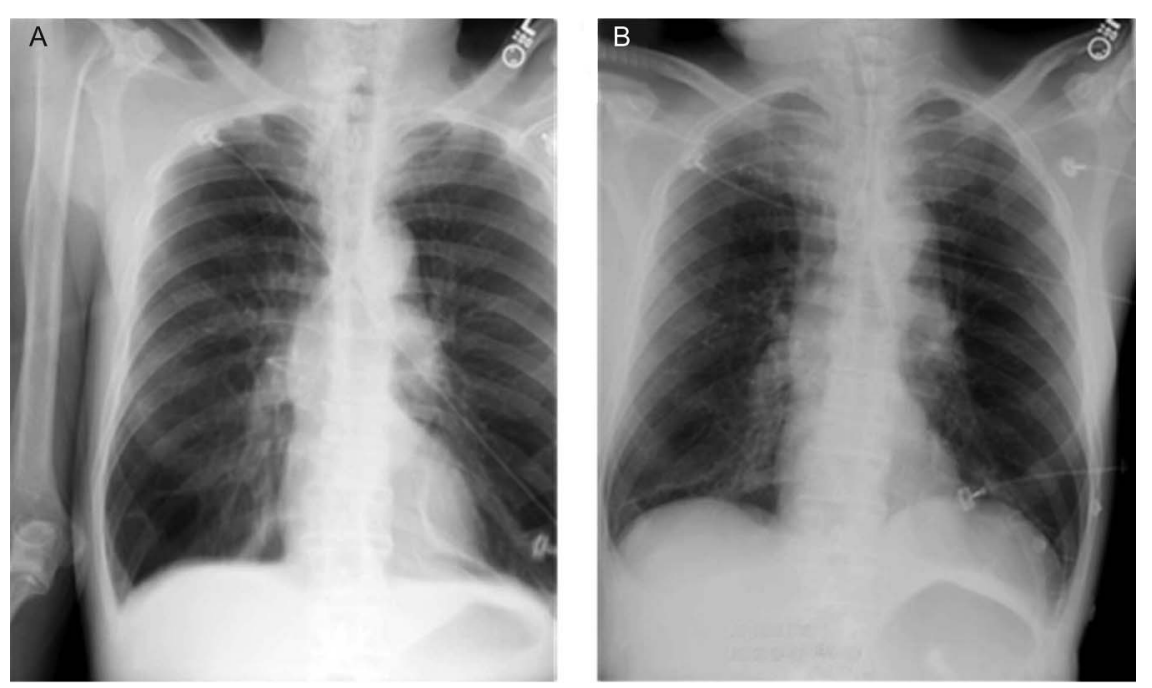

Fig. 5. A: Chest roentgenogram of a patient with COPD who became agitated and developed dynamic hyperinflation. Notice the flattened diaphragm. B: Chest roentgenogram of the same patient after pursed-lip breathing. Note the improvement in hyperinflation and more natural shape of the diaphragm.

pnea and improve exercise tolerance in subjects with COPD. ${ }^{89,90}$ Some of these studies have demonstrated improvement in inspiratory capacity, arterial blood gas oxygen tension, and ventilatory patterns with the use of noninvasive ventilation during exercise. ${ }^{91,92}$ CPAP improves respiratory mechanics by reducing the inspiratory threshold load. With application of external PEEP, there is a decreased pressure gradient between the airway opening and alveoli, therefore decreasing the amount of negative pressure the inspiratory muscles need to generate to cause an inspiratory flow of air. ${ }^{93}$

\section{Addressing the Affective and Emotional Dimension of Dyspnea}

Beyond inducing distress that may increase respiratory drive or alter the perception of dyspnea, the effect of emotions on dyspnea remain somewhat ambiguous. There is some evidence to suggest that alteration of the emotional state may improve dyspnea and objective measures of exercise capacity. ${ }^{43,94}$ Pulmonary rehabilitation may address issues of anxiety and distress and has actually been shown to improve depression and anxiety, independent of changes in dyspnea or health-related quality of life. ${ }^{95-97}$ Though not directly observed, it is theorized that addressing affective and emotional components of dyspnea may optimize breathing patterns to reduce dynamic hyperinflation and improve exercise capacity. ${ }^{98}$

\section{Lung-Volume Reduction}

Lung-volume-reduction surgery is a treatment modality, first introduced in 1957, reserved for patients with severe upper-lobe-predominant emphysema. ${ }^{99}$ Lung-volumereduction surgery has been shown to improve dyspnea and exercise tolerance in select patients with severe emphysema. ${ }^{100-104}$ The mechanisms proposed to explain this benefit include: (1) an increase elastic recoil of the lung, (2) a reduction in air trapping, (3) improved ventilation and perfusion matching, and (4) improved inspiratory muscle function. ${ }^{104,105}$ In patients with severe emphysema who underwent lung-volume-reduction surgery, dynamic hyperinflation was reduced (as evidenced by the end-expiratory lung volume/total lung capacity ratio), inspiratory reserve volume was increased, and patients adopted a slower, deeper breathing pattern with exercise. ${ }^{105}$ Cardiocirculatory effects of dynamic hyperinflation have also been alleviated in response to lung-volume-reduction surgery. Lung-volume-reduction surgery has been shown to increase left ventricular end-diastolic volume and improvement in left ventricular function. ${ }^{106}$

\section{Conclusions}

Dynamic hyperinflation is a significant cause of morbidity and mortality in patients with chronic obstructive pulmonary disease. Dynamic hyperinflation contributes to acute, chronic, and exertional dyspnea. A thorough understanding of the pathophysiology of dynamic hyperinflation and its contributions to dyspnea can help practitioners prescribe a treatment plan that addresses the functional, structural, and emotional issues that come together to contribute to this complex disease process. Areas for further study to alleviate the sensory and physiological consequences of dynamic hyperinflation include expanding the use of opioids for episodes of acute dyspnea as well as the use of 


\section{Respiratory Sensations in Dynamic Hyperinflation}

noninvasive ventilation during exercise in patients with expiratory air-flow limitation.

\section{REFERENCES}

1. Parshall MB, Schwartzstein RM, Adams L, Banzett RB, Manning HL, Bourbeau J, et al. An official American Thoracic society statement: update on the mechanisms, assessment, and management of dyspnea. Am J Respir Crit Care Med 2012;185(4):435-452.

2. O'Donnell DE, Laveneziana P. The clinical importance of dynamic lung hyperinflation in COPD. COPD J Chronic Obstr Pulm Dis 2006;3(4):219-232.

3. Casanova C, Cote C, de Torres JP, Aguirre-Jaime A, Marin JM, Pinto-Plata V, Celli BR. Inspiratory-to-total lung capacity ratio predicts mortality in patients with chronic obstructive pulmonary disease. Am J Respir Crit Care Med 2005;171(6):591-597.

4. Ozgür ES, Nayci SA, Özge C, Taşdelen B. An integrated index combined by dynamic hyperinflation and exercise capacity in the prediction of morbidity and mortality in COPD. Respir Care 2012; 57(9):1452-1459.

5. Gagnon P, Guenette JA, Langer D, Laviolette L, Mainguy V, Maltais $\mathrm{F}$, et al. Pathogenesis of hyperinflation in chronic obstructive pulmonary disease. Int J Chron Obstruct Pulmon Dis 2014;9:187.

6. Nishimura K, Yasui M, Nishimura T, and Oga T. Airflow limitation or static hyperinflation: which is more closely related to dyspnea with activities of daily living in patients with COPD? Respir Res 2011;12(1): 135 .

7. Chen R, Lin L, Tian J, Zeng B, Zhang L, Chen X, and Yan H. Predictors of dynamic hyperinflation during the 6-minute walk test in stable chronic obstructive pulmonary disease patients. J Thorac Dis $2015 ; 7(7): 1142-1150$.

8. Pepin V, Saey D, Laviolette L, and Maltais F. Exercise capacity in chronic obstructive pulmonary disease: mechanisms of limitation. COPD 2007;4(3):195-204.

9. Pedersen OF, Butler JP. Expiratory flow limitation. Compr Physiol 2011;1(4):1861-1882.

10. Schwartzstein, RM, Parker MJ. Respiratory Physiology: A Clinical Approach. Philadelphia: Lippincott Williams \& Wilkins, 2006.

11. Tantucci C. Expiratory flow limitation definition, mechanisms, methods, and significance. Pulm Med 2013;2013:1-6.

12. Macklem PT. Hyperinflation. Am Rev Respir Dis 1984;129(1):1-2.

13. Campbell EJ, Howell JB. The sensation of breathlessness. Br Med Bull 1963;19:36-40.

14. Manning HL, Schwartzstein RM. Pathophysiology of dyspnea. N Engl J Med 1995;333(23):1547-1553.

15. Manning HL, Schwartzstein RM. Respiratory sensations in asthma: physiological and clinical implications. J Asthma 2001;38(6):447460.

16. Banzett RB, Pedersen SH, Schwartzstein RM, Lansing RW. The affective dimension of laboratory dyspnea: air hunger is more unpleasant than work/effort. Am J Respir Crit Care Med 2008;177(12): 1384-1390.

17. Buchanan GF, Richerson GB. Role of chemoreceptors in mediating dyspnea. Respir Physiol Neurobiol 2009;167(1):1-9.

18. Mahler DA, O'Donnell DE. Recent advances in dyspnea. Chest 2015;147(1):232-241.

19. Widdicombe J. Lung afferent activity: implications for respiratory sensation. Respir Physiol Neurobiol 2009;167(1):2-8.

20. Lee LY. Respiratory sensations evoked by activation of bronchopulmonary C-fibers. Respir Physiol Neurobiol 2009;167(1):26-35.

21. Simon PM, Schwartzstein RM, Weiss JW, Fencl V, Teghtsoonian M, Weinberger SE. Distinguishable types of dyspnea in patients with shortness of breath. Am Rev Respir Dis 1990;142(5):10091014.
22. Rock LK, Schwartzstein RM. Mechanisms of dyspnea in chronic lung disease. Curr Opin Support Palliat Care 2007;1(2):102-108.

23. Mahler DA, Harver A, Lentine T, Scott JA, Beck K, Schwartzstein RM. Descriptors of breathlessness in cardiorespiratory diseases. Am J Respir Crit Care Med 1996;154(5):1357-1363.

24. O'Donnell DE, Guenette JA, Maltais F, Webb KA. Decline of resting inspiratory capacity in COPD: the impact on breathing pattern, dyspnea, and ventilatory capacity during exercise. Chest 2012; 141(3):753-762.

25. O’Donnell DE, Laveneziana P. Physiology and consequences of lung hyperinflation in COPD. Eur Respir Rev 2006;15(100):61-67.

26. Yan S. Sensation of inspiratory difficulty during inspiratory threshold and hyperinflationary loadings: effect of inspiratory muscle strength. Am J Respir Crit Care Med 1999;160(5):1544-1549.

27. Killian KJ, Jones NL. Respiratory muscles and dyspnea. Clin Chest Med 1988;9(2):237-248.

28. Schwartzstein RM, Manning HL, Weiss JW, Weinberger SE. Dyspnea: a sensory experience. Lung 1990;168(4):185-199.

29. Montes de Oca M, Celli BR. Mouth occlusion pressure, CO2 response and hypercapnia in severe chronic obstructive pulmonary disease. Eur Respir J 1998;12(3):666-671.

30. De Troyer A, Leeper JB, McKenzie DK, Gandevia SC. Neural drive to the diaphragm in patients with severe COPD. Am J Respir Crit Care Med 1997;155(4):1335-1340.

31. O'Donnell DE, D'Arsigny C, Fitzpatrick M, Webb KA. Exercise hypercapnia in advanced chronic obstructive pulmonary disease: the role of lung hyperinflation. Am J Respir Crit Care Med 2002; 166(5):663-668.

32. Caviedes IR, Delgado I, Soto R. Ventilatory inefficiency as a limiting factor for exercise in patients with COPD. Respir Care 2012; 57(4):583-589.

33. Elbehairy AF, Ciavaglia CE, Webb KA, Guenette JA, Jensen D, Mourad SM et al. Pulmonary gas exchange abnormalities in mild chronic obstructive pulmonary disease: implications for dyspnea and exercise intolerance. Am J Respir Crit Care Med 2015;191(12): 1384-1394.

34. Zafar MA, Tsuang W, Lach L, Eschenbacher W, Panos RJ. Dynamic hyperinflation correlates with exertional oxygen desaturation in patients with chronic obstructive pulmonary disease. Lung 2013; 191(2):177-182.

35. O'Donnell DE, Laveneziana P, Webb K, Neder JA. Chronic obstructive pulmonary disease: clinical integrative physiology. Clin Chest Med 35(1):51-69, 2014.

36. Watz H, Waschki B, Meyer T, Kretschmar G, Kirsten A, Claussen M, Magnussen H. Decreasing cardiac chamber sizes and associated heart dysfunction in COPD: role of hyperinflation. Chest 2010; 138(1):32-38.

37. Jörgensen K, Müller MF, Nel J, Upton RN, Houltz E, Ricksten S-E. Reduced intrathoracic blood volume and left and right ventricular dimensions in patients with severe emphysema: an MRI study. Chest 2007;131(4):1050-1057.

38. Aliverti A, Macklem PT. Last word on point:counterpoint: the major limitation to exercise performance in COPD is 1) inadequate energy supply to the respiratory and locomotor muscles, 2) lower limb muscle dysfunction, 3) dynamic hyperinflation. J Appl Physiol 2008;105(3):763.

39. Skeletal muscle dysfunction in chronic obstructive pulmonary disease. A statement of the American Thoracic Society and European Respiratory Society. Am J Respir Crit Care Med 1999;159(4):S1S40.

40. Maltais F, Jobin J, Sullivan MJ, Bernard S, Whittom F, Killian KJ, et al. Metabolic and hemodynamic responses of lower limb during exercise in patients with COPD. J Appl Physiol 1998;84(5):15731580. 


\section{Respiratory Sensations in Dynamic Hyperinflation}

41. Aliverti A, Macklem PT. How and why exercise is impaired in COPD. Respir Int Rev Thorac Dis 2001;68(3):229-239.

42. Hulo S, Inamo J, Dehon A, Le Rouzic O, Edme J-L, Neviere R. Chronotropic incompetence can limit exercise tolerance in COPD patients with lung hyperinflation. Int J Chron Obstruct Pulmon Dis 2016;11:2553-2561.

43. von Leupoldt A, Sommer T, Kegat S, Baumann HJ, Kose H, Dahme B, Büchel C. Dyspnea and pain share emotion-related brain network. NeuroImage 2009;48(1):200-206.

44. Davenport PW, Vovk A. Cortical and subcortical central neural pathways in respiratory sensations. Respir Physiol Neurobiol 2009; 167(1):72-86.

45. Evans KC, Banzett RB, Adams L, McKay L, Frackowiak RSJ, Corfield DR. BOLD fMRI identifies limbic, paralimbic, and cerebellar activation during air hunger. J Neurophysiol 2002;88(3):15001511.

46. Cooper CB, Calligaro GL, Quinn MM, Eshaghian P, Coskun F, Abrazado M, et al. Determinants of dynamic hyperinflation during metronome-paced tachypnea in COPD and normal subjects. Respir Physiol Neurobiol 2014;190:76-80

47. Calligaro GL, Raine RI, Bateman ME, Bateman ED, Cooper CB. Comparing dynamic hyperinflation and associated dyspnea induced by metronome-paced tachypnea versus incremental exercise. COPD 2014;11(1):105-112.

48. Leith DE, Brown R. Human lung volumes and the mechanisms that set them. Eur Respir J 1999;13:468-472.

49. Marin JM, Carrizo SJ, Gascon M, Sanchez A, Gallego B, Celli BR. Inspiratory capacity, dynamic hyperinflation, breathlessness, and exercise performance during the 6-minute-walk test in chronic obstructive pulmonary disease. Am J Respir Crit Care Med 2001; 163(6):1395-1399.

50. Callens E, Graba S, Gillet-Juvin K, Essalhi M, Bidaud-Chevalier B, Peiffer $\mathrm{C}$, et al. Measurement of dynamic hyperinflation after a 6-minute walk test in patients with COPD. Chest 2009;136(6): 1466-1472.

51. O'Donnell DE, Elbehairy AF, Faisal A, Webb KA, Neder JA, Mahler DA. Exertional dyspnoea in COPD: the clinical utility of cardiopulmonary exercise testing. Eur Respir Rev 2016;25(141): 333-347.

52. Gelb AF, Gutierrez CA, Weisman IM, Newsom R, Taylor CF, Zamel N. Simplified detection of dynamic hyperinflation. Chest 2004;126(6):1855-1860.

53. Lahaije AJMC, Willems LM, van Hees HWH, Dekhuijzen PNR, Heidra YF. Diagnostic accuracy of metronome-paced tachypnea to detect dynamic hyperinflation. Clin Physiol Funct Imaging 2013; 33(1)62-69.

54. Lahaije A, van Helvoort H, Dekhuijzen R, Heijdra Y. Can COPD patients who hyperinflate during daily life activities be identified by laboratory tests? Respir Int Rev Thorac Dis 2013;86(3):237-242.

55. O'Donnell DE, Hamilton AL, Webb KA. Sensory-mechanical relationships during high-intensity, constant-work-rate exercise in COPD. J Appl Physiol 2006;101(4):1025-1035.

56. O'Donnell DE, Lam, M, Webb KA. Spirometric correlates of improvement in exercise performance after anticholinergic therapy in chronic obstructive pulmonary disease. Am J Respir Crit Care Med 1999;160(2):542-549.

57. O'Donnell DE, Lam M, Webb KA. Measurement of symptoms, lung hyperinflation, and endurance during exercise in chronic obstructive pulmonary disease. Am J Respir Crit Care Med 1998; 158(5):1557-1565.

58. O’Donnell DE, Flüge T, Gerken F, Hamilton A, Webb K, Aguilaniu $\mathrm{B}$, et al. Effects of tiotropium on lung hyperinflation, dyspnoea and exercise tolerance in COPD. Eur Respir J 2004;23(6):832-840.
59. Laveneziana P, Palange P, Ora J, Martolini D, O'Donnell DE. Bronchodilator effect on ventilatory, pulmonary gas exchange, and heart rate kinetics during high-intensity exercise in COPD. Eur J Appl Physiol 2009;107(6):633-643.

60. Sanguinetti CM. The lungs need to be deflated: effects of glycopyrronium on lung hyperinflation in COPD patients. Multidiscip Respir Med 2014;9(1):19.

61. Berton DC, Barbosa PB, Takara LS, Chiappa GR, Siqueira ACB, Bravo DM, et al. Bronchodilators accelerate the dynamics of muscle $\mathrm{O} 2$ delivery and utilisation during exercise in COPD. Thorax 2010;65(7):588-593.

62. Chiappa GR, Queiroga F, Meda E, Ferreira LF, Diefenthaeler F, Nunes $\mathrm{M}$, et al. Heliox improves oxygen delivery and utilization during dynamic exercise in patients with chronic obstructive pulmonary disease. Am J Respir Crit Care Med 2009;179(11):10041010.

63. Vogiatzis I, Habazett H, Aliverti A, Anthanasopoulos D, Louvaris Z, LoMauro A, et al. Effect of helium breathing on intercostal and quadriceps muscle blood flow during exercise in COPD patients. Am J Physiol Regul Integr Comp Physiol 2011;300(6):R1549R1559.

64. Banzett RB, Adams L, O'Donnell CR, Gilman SA, Lansing RW, Schwartzstein RM. Using laboratory models to test treatment: morphine reduces dyspnea and hypercapnic ventilatory response. Am J Respir Crit Care Med 2011;184(8):920-927.

65. Pattinson KTS, Governo RJ, MacIntosh BJ, Russell EC, Corfield DR, Tracey I, Wise RG. Opioids Depress cortical centers responsible for the volitional control of respiration. J Neurosci 2009; 29(25):8177-8186.

66. Jennings A-L, Davies AN, Higgins JPT, Gibbs JSR, Broadley KE. A systematic review of the use of opioids in the management of dyspnoea. Thorax 2002;57(11):939-944.

67. Mahler DA. Opioids for refractory dyspnea. Expert Rev Respir Med 2013;7(2):123-134.

68. Abernethy AP, Currow DC, Frith P, Fazekas BS, McHugh A, Bui C. Randomised, double blind, placebo controlled crossover trial of sustained release morphine for the management of refractory dyspnoea. BMJ 2003;327(7414):523-528.

69. Cabezón-Gutiérrez L, Khosravi-Shahi P, Custodio-Cabello S, Muñiz-González F, Cano-Aguirre MP, Alonso-Viteri S. Opioids for management of episodic breathlessness or dyspnea in patients with advanced disease. Support Care Cancer 2016;24(9):4045-4055.

70. Janssen DJA, Spruit MA, Uszko-Lencer NH, Schols JMGA, Wouters EFM. Symptoms, comorbidities, and health care in advanced chronic obstructive pulmonary disease or chronic heart failure. J Palliat Med 2011;14(6):735-743.

71. Soffler MI, Rose A, Hayes MM, Banzett RB, Schwartzstein RM. Treatment of acute dyspnea with morphine to avert respiratory failure. Ann Am Thorac Soc 2017;14(4):584-588.

72. Kallet RH. The role of inhaled opioids and furosemide for the treatment of dyspnea. Respir Care 2007;52(7):900-910.

73. Kohara H, Euoka H, Aoe K, Maeda T, Takeyama H, Saito R, et al. Effect of nebulized furosemide in terminally ill cancer patients with dyspnea. J Pain Symptom Manage 2003;26(4):962-967.

74. Ong K-C, Kor A-C, Chong W-F, Earnest A, Wang Y-T. Effects of inhaled furosemide on exertional dyspnea in chronic obstructive pulmonary disease. Am J Respir Crit Care Med 2004;169(9):10281033.

75. Jensen D, Amjadi K, Harris-McAllister V, Webb KA, O'Donnell DE. Mechanisms of dyspnea relief and improved exercise endurance after furosemide inhalation in COPD. Thorax 2008;63(7):606613.

76. Nasis I, Kortianou E, Vasilopoulou M, Spetsioti S, Louvaris Z, Kaltsakas G, et al. Hemodynamic effects of high intensity interval 


\section{Respiratory Sensations in Dynamic Hyperinflation}

training in COPD patients exhibiting exercise-induced dynamic hyperinflation. Respir Physiol Neurobiol 2015;217:8-16.

77. Porszasz J, Emtner M, Goto S, Somfay A, Whipp BJ, Casaburi R. Exercise training decreases ventilatory requirements and exerciseinduced hyperinflation at submaximal intensities in patients with COPD. Chest 2005;128(4):2025-2034.

78. Ramponi S, Tzani P, Aiello M, Marangio E, Clini E, Chetta A. Pulmonary rehabilitation improves cardiovascular response to exercise in COPD. Respir Int Rev Thorac Dis 2013;86(1):17-24.

79. Lötters F, van Tol B, Kwakkel G, Gosselink R. Effects of controlled inspiratory muscle training in patients with COPD: a metaanalysis. Eur Respir J 2002;20(3):570-576.

80. Chun EM, Han SJ, Modi HN. Analysis of diaphragmatic movement before and after pulmonary rehabilitation using fluoroscopy imaging in patients with COPD. Int J Chron Obstruct Pulmon Dis 2015; 10:193-199.

81. Fagevik Olsén M, Lannefors L, Westerdahl E. Positive expiratory pressure - Common clinical applications and physiological effects. Respir Med 2015;109(3):297-307.

82. Monteiro MB, Berton DC, Moreira MAF, Menna-Barreto SS, Teixeira PJZ. Effects of expiratory positive airway pressure on dynamic hyperinflation during exercise in patients with COPD. Respir Care 2012;57(9):1405-1412.

83. Faager G, Stâhle A, Larsen FF. Influence of spontaneous pursed lips breathing on walking endurance and oxygen saturation in patients with moderate to severe chronic obstructive pulmonary disease. Clin Rehabil 2008;22(8):675-683.

84. Tiep BL, Burns M, Kao D, Madison R, Herrera J. Pursed lips breathing training using ear oximetry. Chest 1986;90(2):218-221.

85. Cabral LF, D’Elia TDC, Marins DDS, Zin WA, Guimarães FS. Pursed lip breathing improves exercise tolerance in COPD: a randomized crossover study. Eur J Phys Rehabil Med 2015;51(1):7988 .

86. Marchetti N, Lammi MR, Travaline JM, Ciccolella D, Civic B, Criner GJ. Air current applied to the face improves exercise performance in patients with COPD. Lung 2015;193(5):725-731.

87. Ram FSF, Picot J, Lightowler J, Wedzicha JA. Non-invasive positive pressure ventilation for treatment of respiratory failure due to exacerbations of chronic obstructive pulmonary disease. Cochrane Database Syst Rev 2004;(3):CD004104.

88. Barnes PJ. GOLD 2017: a new report. Chest 2017;151(2):245-246.

89. van 't Hul A, Kwakkel G, Gosselink R. The acute effects of noninvasive ventilatory support during exercise on exercise endurance and dyspnea in patients with chronic obstructive pulmonary disease: a systematic review. J Cardiopulm Rehabil 2002;22(4):290297.

90. Díaz O, Ramos J, Gallardo J, Torrealba B, Lisboa C. [Non-invasive mechanical ventilation in patients with severe stable COPD]. Rev Med Chil 1999;127(6):647-654.

91. Díaz O, Bégin P, Torrealba B, Jover E, Lisboa C. Effects of noninvasive ventilation on lung hyperinflation in stable hypercapnic COPD. Eur Respir J 2002;20(6):1490-1498.
92. Petrof BJ, Calderini E, Gottfried SB. Effect of CPAP on respiratory effort and dyspnea during exercise in severe COPD. J Appl Physiol 1990;69(1):179-188.

93. O'Donoghue FJ, Catcheside PG, Jordan AS, Bersten AD, McEvoy RD. Effect of CPAP on intrinsic PEEP, inspiratory effort, and lung volume in severe stable COPD. Thorax 2002;57(6):533-539.

94. Emery CF, Schein RL, Hauck ER, MacIntyre NR. Psychological and cognitive outcomes of a randomized trial of exercise among patients with chronic obstructive pulmonary disease. Health Psychol 1998;17(3):232-240.

95. Paz-Díaz H, Montes de Oca M, López JM, Celli BR. Pulmonary rehabilitation improves depression, anxiety, dyspnea and health status in patients with COPD. Am J Phys Med Rehabil 2007;86(1): 30-36.

96. Luk EK, Khan F, Irving L. Maintaining gains following pulmonary rehabilitation. Lung 2015;193(5):709-715.

97. Bhandari NJ, Jain T, Marolda C, ZuWallack RL. Comprehensive pulmonary rehabilitation results in clinically meaningful improvements in anxiety and depression in patients with chronic obstructive pulmonary disease. J Cardiopulm Rehabil Prev 2013;33(2):123127.

98. von Leupoldt A, Fritzsche A, Trueba AF, Meuret AE, Ritz T. Behavioral medicine approaches to chronic obstructive pulmonary disease. Ann Behav Med 2012;44(1):52-65.

99. Brantigan OC, Mueller E. Surgical treatment of pulmonary emphysema. Am Surg 1957;23(9):789-804.

100. Hopkinson NS, Toma TP, Hansell DM, Goldstraw P, Moxham J, Geddes DM, Polkey MI. Effect of bronchoscopic lung volume reduction on dynamic hyperinflation and exercise in emphysema. Am J Respir Crit Care Med 2005;171(5):453-460.

101. Shah PL, Herth FJ, van Geffen WH, Deslee G, Slebos, D-J. Lung volume reduction for emphysema. Lancet Respir Med 2017;5(2): 147-156.

102. Toma TP, Hopkinson NS, Hillier J, Hansell DM, Morgan C, Goldstraw PG, et al. Bronchoscopic volume reduction with valve implants in patients with severe emphysema. Lancet 2003;361(9361): 931-933.

103. Pompeo E, Marino M, Nofroni I, Matteucci G, Mineo TC. Reduction pneumoplasty versus respiratory rehabilitation in severe emphysema: a randomized study. Pulmonary Emphysema Research Group. Ann Thorac Surg 2000;70(3):948-953.

104. Martinez FJ, de Oca MM, Whyte RI, Stetz J, Gay SE, Celli BR. Lung-volume reduction improves dyspnea, dynamic hyperinflation, and respiratory muscle function. Am J Respir Crit Care Med 1997; 155(6):1984-1990.

105. Lammi MR, Marchetti N, Criner GJ. Reduced dynamic hyperinflation after LVRS is associated with improved exercise tolerance. Respir Med 2014;108(10):1491.

106. Jörgensen K, Houltz E, Westfelt U, Nilsson F, Scherstèn H, Ricksten S-E. Effects of lung volume reduction surgery on left ventricular diastolic filling and dimensions in patients with severe emphysema. Chest 2003;124(5):1863-1870 